\title{
Hemispheric-scale comparison and evaluation of passive-microwave snow algorithms
}

\author{
Richard L. Armstrong, Mary J. Brodzik \\ National Snow and Ice Data Center, CIRES, University of Colorado, Boulder, CO 80309-0449, U.S.A.
}

\begin{abstract}
Passive-microwave satellite remote sensing can greatly enhance largescale snow measurements based on visible satellite data alone because of the ability to acquire data through most clouds or during darkness as well as to provide a measure of snow depth or water equivalent. This study provides preliminary results from the comparison and evaluation of several different passive-microwave algorithms. These algorithms represent examples which include both mid- and high-frequency channels, vertical and horizontal polarizations and polarization-difference approaches. In our comparisons we utilize larger, more comprehensive, validation datasets which can be expected to provide a full range of snow/climate conditions rather than limited data which may only represent a "snapshot" in time and space. Evaluation of snow extent derived from passive-microwave data is undertaken through comparison with the U.S. National Oceanic and Atmospheric Administration (NOAA) Northern Hemisphere snow charts which are based on visible-band satellite data. Results clearly indicate those time periods and geographic regions where the two techniques agree and where they tend to consistently disagree. Validation of snow water equivalent derived from passive-microwave data is undertaken using measurements from snowcourse transects in the former Soviet Union. Preliminary results indicate a general tendency for nearly all of the algorithms to underestimate snow water equivalent.
\end{abstract}

\section{INTRODUGTION}

Snow cover is an important variable for climate and hydrologic models due to its effects on energy and moisture budgets. Seasonal snow, which can cover $>50 \%$ of the Northern Hemisphere land surface during winter (Armstrong and Brodzik, 1999; Frei and Robinson, 1999) is responsible for the largest annual and interannual differences in land surface albedo. Surface temperature is highly dependent on the presence or absence of snow cover, and temperature trends have been shown to be related to changes in snow cover (Groisman and others, 1994). Realistic simulation of snow cover in climate models is essential for correct representation of the surface energy balance, as well as for understanding winter water storage and predicting year-round runoff. The lack of meteorological and snow data to execute, calibrate and validate snow-cover models is a major obstacle to improved simulations (Barron and others, 1999).

When snow covers the ground, some of the microwave energy emitted by the underlying soil is scattered by the snow grains. Therefore, when moving from snow-free to snow-covered land surfaces, a sharp decrease in emissivity and associated brightness temperatures provides a nearly unambiguous indicator of the presence of dry snow (Mätzler, 1994). In addition, snow exhibits what is termed a negative spectral gradient which means that as the microwave frequency increases (e.g. from 19 to $37 \mathrm{GHz}$ ), the emissivity and associated brightness temperatures decrease. Nearly all other land-surface types exhibit a positive spectral gradient (Mätzler, 1994). Various theoretical and empirical studies have demonstrated that the amount of scattering can be correlated with snow mass and specific wavelength. From this basic relationship, regional algorithms have been developed which indicate the presence of snow and compute snow water equivalent (SWE) (Chang and others, 1987; Goodison, 1989; Nagler, 1991; Grody and Basist, 1996; Hiltbrunner, 1996; Tait, 1998; Pullainen and Hallikainen, 2001). Nearly all of these algorithms have been developed and tested for dry-snow conditions only. SWE cannot be determined when the snow is wet (i.e. liquid water is present on the snow grain surface) because wet snow is primarily an emitter with respect to microwave energy, so the information derived from the characteristic scattering signature of dry snow is lost. However, it is still possible to detect the presence of wet snow due to its distinct polarization difference (Walker and Goodison, 1993; Mätzler, 1994).

\section{DATA SOURGES}

\section{Brightness temperatures}

The U.S. National Oceanic and Atmospheric Administration (NOAA)/NASA Pathfinder Program was initiated in 1993 to facilitate the application of currently archived satellite data for global-change research. With support from this program the National Snow and Ice Data Center (NSIDG) has produced a 23 year, consistently processed, time series of gridded satellite passive-microwave data in a common format called the Equal-Area Scalable Earth Grid (EASE-Grid; see http: //nsidc.org/NASA/GUIDE/EASE/easemaps.info.html). This dataset was developed using Scanning Multichannel Microwave Radiometer (SMMR) data for the period 1978-87, and Special Sensor Microwave Imager (SSM/I) data for 1987-2000. These EASE-Grid brightness temperatures pro- 


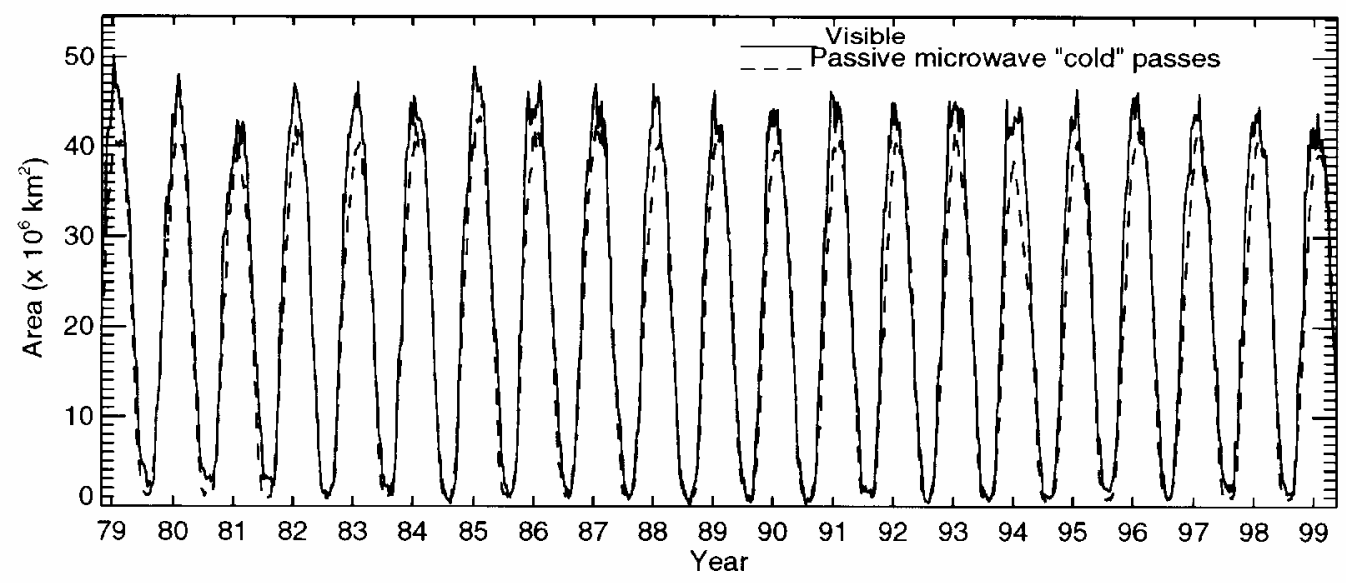

Fig. 1. Northern Hemisphere snow-covered area derived from visible (NOAA) and passive-microwave (SMMR and SSM/I) satellite data, 1978-99.

vide the standard input to all algorithms being evaluated in this study.

\section{Validation data}

For the validation of snow-covered area, we compare microwave snow-extent maps with the EASE-Grid version (Armstrong and Brodzik, 1998) of the NOAA Northern Hemisphere weekly snow charts (Robinson and others, 1993). The original NOAA charts were derived from the manual interpretation of Advanced Very High-Resolution Radiometer (AVHRR), Geostationary Operational Environmental Satellite (GOES) and other visible satellite data. With regard to SWE, we focus on the robust nature of the larger validation datasets which can be expected to provide a full seasonal to annual range of snow/climate conditions, rather than on smaller datasets which may only represent a "snapshot" in time and space. The validation dataset being used in the current phase of our study is the "Former Soviet Union Hydrological Surveys" (FSUHS) (Haggerty and Armstrong, 1996). These data represent a unique and invaluable source for algorithm validation as they include not only SWE values but additional information pertaining to snow structure, extent of snow cover within the surrounding terrain, as well as forest type and percentage forest cover from a $50 \mathrm{~km}$ diameter area surrounding the station. These data are available during both the SMMR and SSM/I periods (through 1990) and comprise the average of measurements along transects $1.0-2.0 \mathrm{~km}$ in length with measurements every 100-200 m. These surveys were undertaken on the 10 th, 20th and 30 th day of the month. Future work will include additional validation data from Canada and the United States.

\section{COMPARISON OF MIGROWAVE AND VISIBLE SNOW DATA}

In this phase of our study we evaluate the overall capability of the passive-microwave data to map snow-covered area through comparison with the EASE-Grid version of the NOAA Northern Hemisphere snow-extent data. This involves the comparison of data derived from two completely different sensor systems and analysis techniques. The NOAA dataset is the result of the manual interpretation of visible satellite data, while the microwave data are the result of the consistent application of individual numerical algorithms throughout the brightness-temperature time series.

For the period 1978-99, both passive-microwave and visible datasets show a similar pattern of interannual variability, and both indicate maximum extents consistently exceeding $40 \times 10^{6} \mathrm{~km}^{2}$ (Fig. 1). The visible data typically show higher variability in the departures from the monthly means, while the long-term trends based on the departures indicate similar decreases in Northern Hemisphere snow extent of approximately $0.25 \%$ per year (NOAA) and $0.13 \%$ per year (passive microwave) (Fig. 2). In order to provide a single example for initial illustration, the Chang and others (1987) algorithm has been used to compute snow-covered area for the SMMR period, and a modified version of this same algorithm has been used during the SSM/I period in Figures 1-3. In this example, and throughout this study, only brightness temperatures from "cold" orbits (night or early morning) are used as input to the algorithms, in order to reduce the probability that the microwave sensor will be viewing a wet-snow surface.

When the monthly climatologies are compared (Fig. 3) it becomes clear that the agreement between the two techniques varies depending on the time of the year. During the shallow-snow conditions of early winter (OctoberDecember) the algorithms tested consistently indicate less snow-covered area than the visible data. This underestimate of snow extent most likely results from the fact that shallow snow cover (less than about $5.0 \mathrm{~cm}$ ) does not provide a scattering signal of sufficient streng th to be detected by this and other algorithms which rely primarily on the 19 and $37 \mathrm{GHz}$ channels. Robinson and others (1993) and Brown (2000) indicate that the threshold for snow detection in the NOAA dataset is approximately $2.0 \mathrm{~cm}$. In addition, because visible data are better suited to detecting shallow snow, they also monitor the fluctuating snow-extent edge more precisely, resulting in greater spatial variability over time, as shown in Figure 2a. The inclusion of the $85 \mathrm{GHz}$ channel, as shown below, with the associated enhanced scattering response, improves the microwave capability to map shallow snow. Although the $85 \mathrm{GHz}$ channel is affected by atmospheric conditions, a cloud-clearing filter can be applied which selects the day with the clearest atmosphere during the monitoring period (Nagler, 1991) or which screens out precipitating clouds (Grody and Basist, 1996).

As the snow cover continues to build during JanuaryMarch, as well as on into the melt season, agreement 

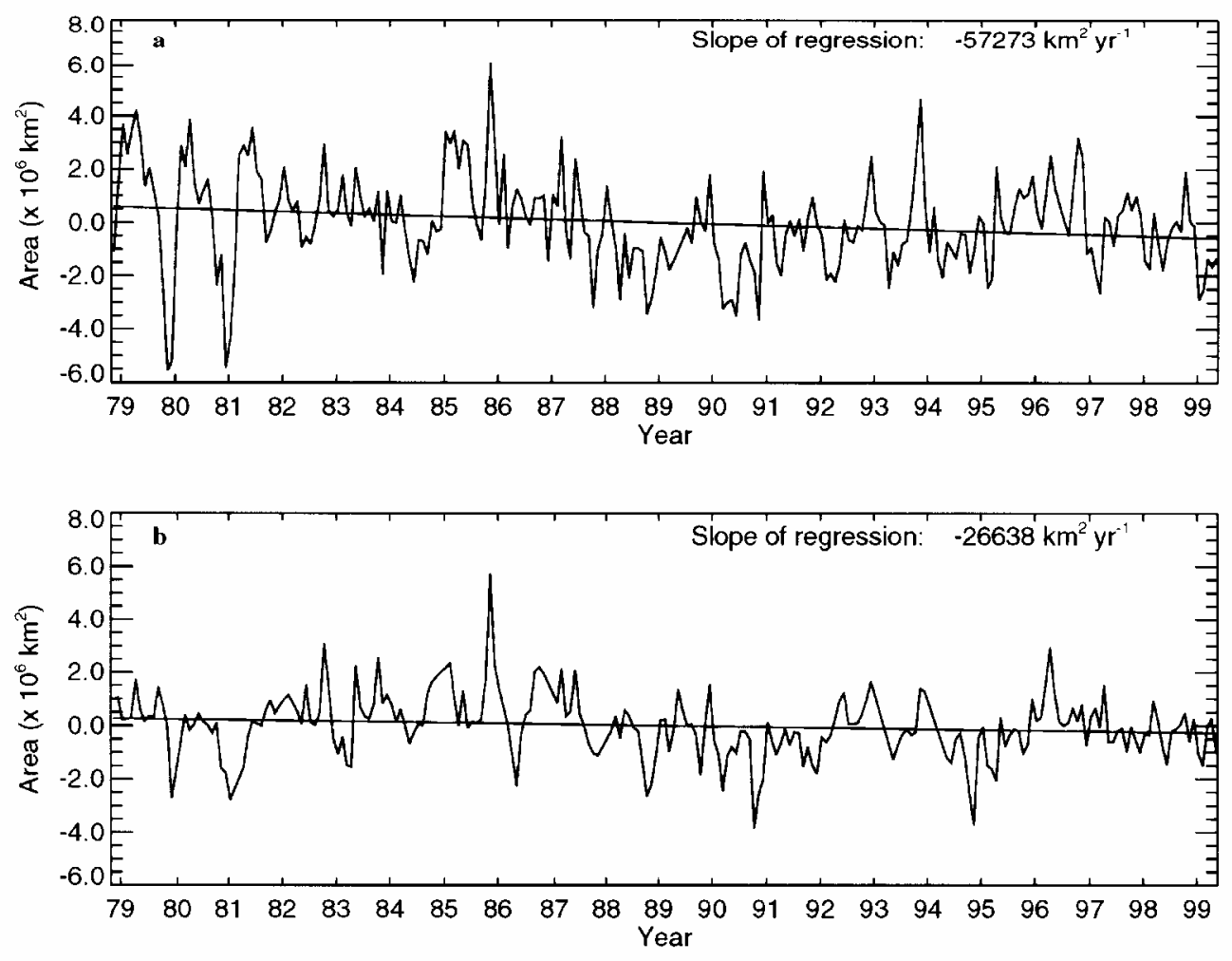

Fig. 2. (a) Visible-derived ( NOAA) and (b) passive-microwave-derived ( SMMR and SSM/I) snow-covered area departures from monthly means for Northern Hemisphere, 1978-99.

between the two data types improves (Fig. 3). Algorithms utilizing vertical polarizations frequently indicate the presence of snow over some snow-free desert soils, apparently due to the enhanced scattering response of the vertical channels. However, in this typical example shown in Figure 3, the microwave data indicate statistically significantly less snowcovered area than the visible data for all months except April, with a mean difference for the monthly climatologies of $2.7 \times 10^{6} \mathrm{~km}^{2}$, ranging from $8.0 \times 10^{6} \mathrm{~km}^{2}$ in November to $0.4 \times 10^{6} \mathrm{~km}^{2}$ in August.

\section{MIGROWAVE ALGORITHM GOMPARISONS}

In this phase of the study we apply digital image comparison techniques to a multi-year, time-series analysis of several different algorithms. The ultimate goal of this study is to determine when the differences between the algorithm output and

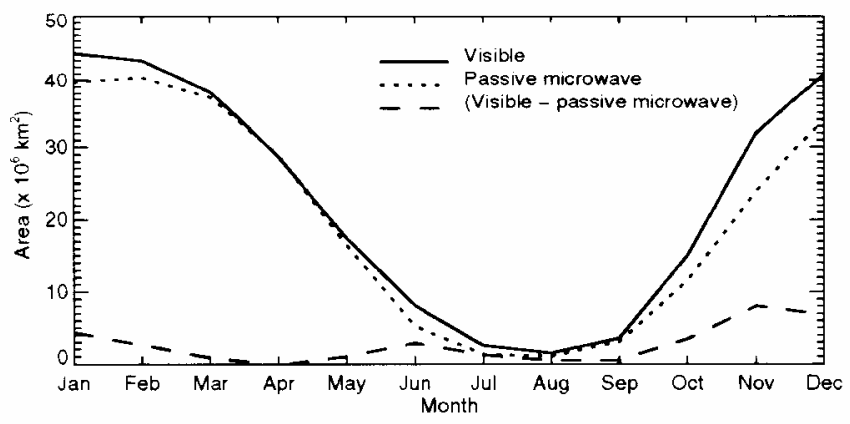

Fig. 3. Northern Hemisphere mean monthly snow-covered area derived from visible ( NOAA) and passive microwave (SMMR and SSM/I), and the difference between the two (visible minus passive microwave), 1978-99. the validation data are random and when they are systematic. In the case of systematic differences, the patterns are being correlated with the specific effects of land-cover type, atmospheric conditions and snow structure. Because we compare algorithm output with continuous records of station data, we are able to identify any seasonal or interannual patterns in the accuracy of the algorithms.

\section{Snow-covered area}

The following is a brief overview of our current algorithmcomparison study for snow extent. Figure 4 contains comparisons of the NOAA weekly snow extent and four passivemicrowave algorithms (Chang and others, 1987; Goodison, 1989; Nagler, 1991; Grody and Basist, 1996). It should be noted that none of these algorithms was originally developed for hemispheric-scale application, and reference to the algorithms by author name is for convenience only. However, because these algorithms individually represent examples which include both mid- and high-frequency channels, vertical and horizontal polarizations and polarization-difference approaches, they allow us to evaluate the relative merits of these different approaches at the hemispheric scale.

In Figure 4, the dotted line in the NOAA images represents the area within which the surface temperatures (NCEP (U.S. National Centers for Environmental Prediction) Re-analysis data) at the approximate time of the satellite overpass had not been above freezing for the week. This information allows us to focus our analysis on those regions where a sub-freezing snow cover can be expected. The black line in the passive-microwave images corresponds to the NOAA snow extent for that week. While each season is represented by only one example week, these are typical of the results which we obtained from comparisons covering several years, as is shown later in Figure 5. 
4a. Fall

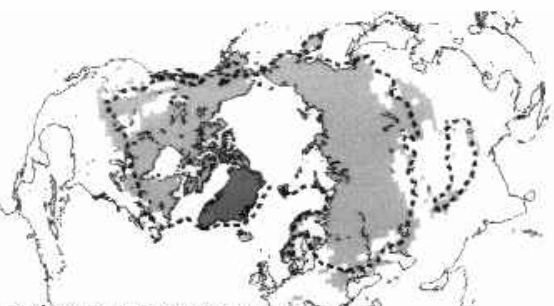

NOAA $931108-14$ Tre
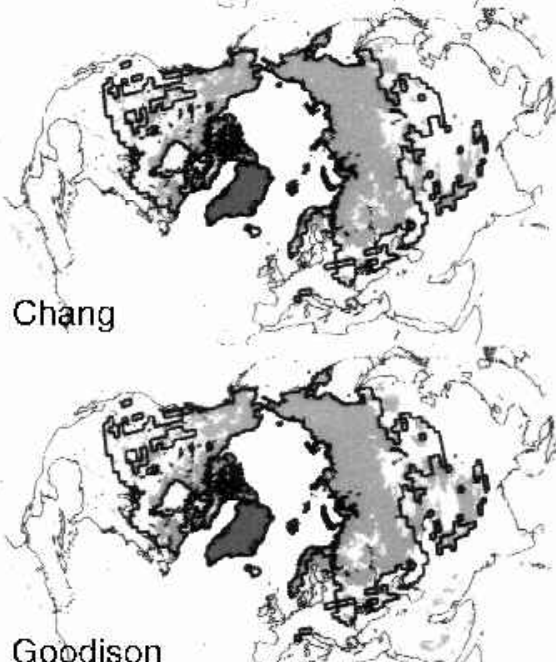

Goodison

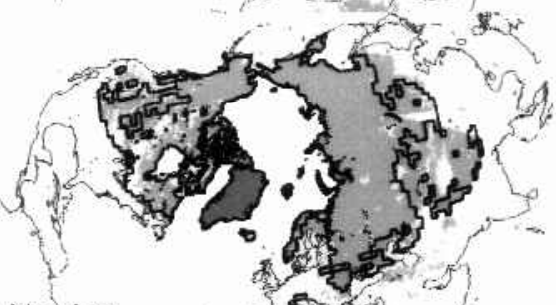

Nagler

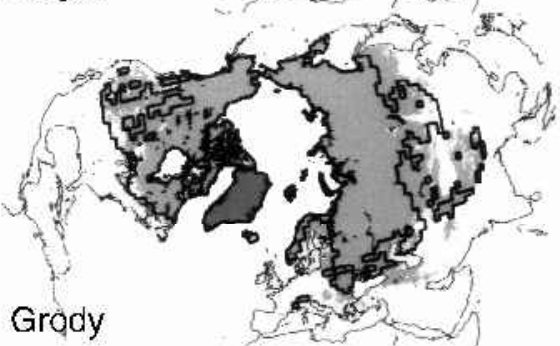

4b. Winter

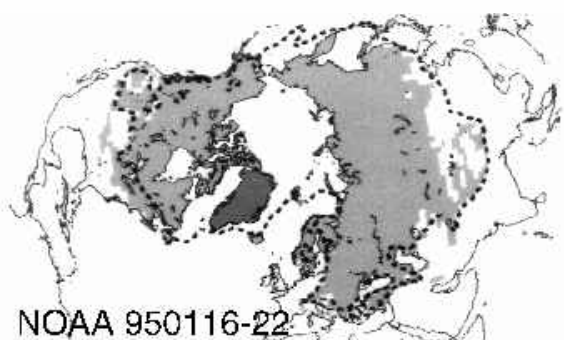

NOAA $950116-20$
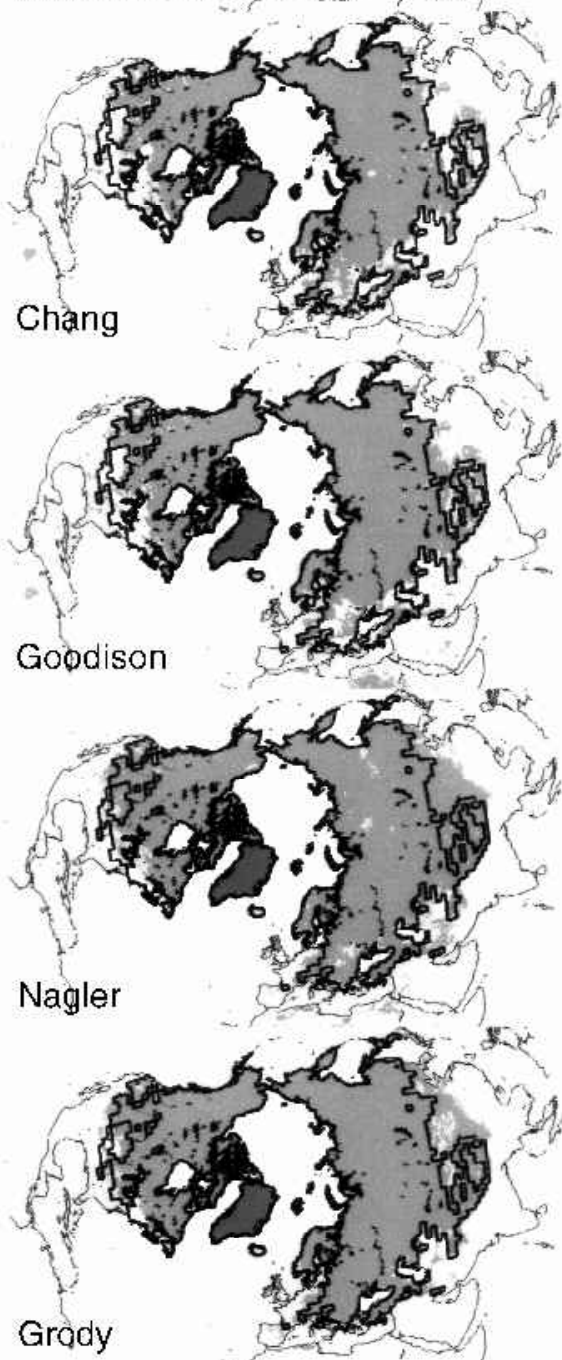

4c. Spring

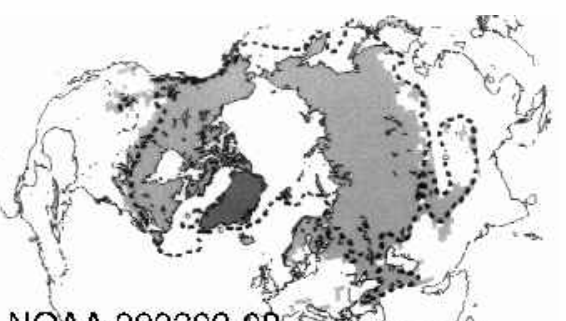

NOAA $920302-08$ \%
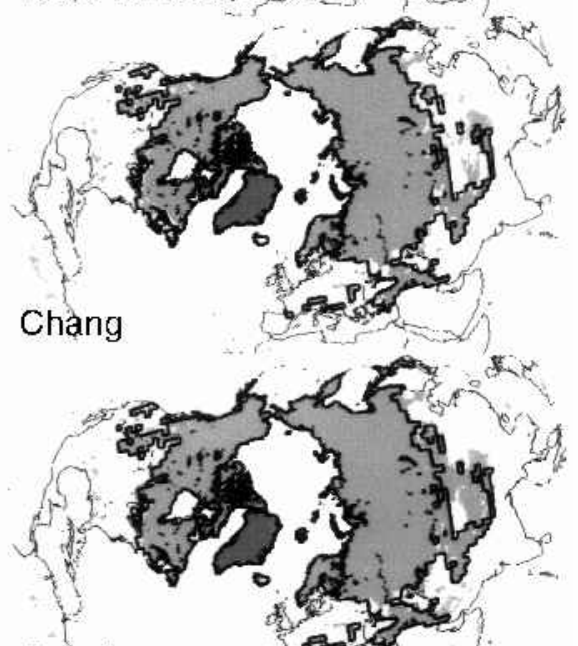

Goødison

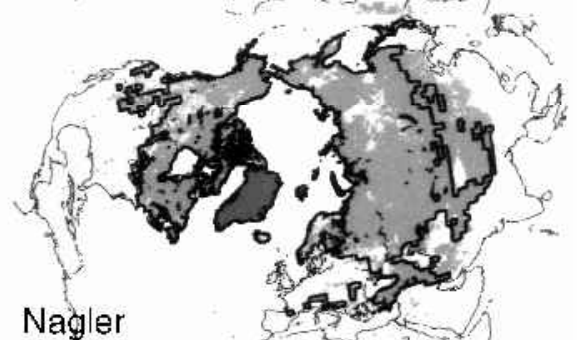

Nagler

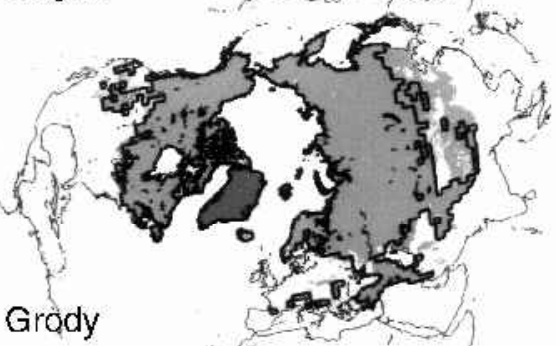

Fig. 4. Typical seasonal comparisons ( ( a ) fall, (b) winter, (c) spring) of NOAA weekly snow extent and four passive-microwave algorithms. Light grey areas in each image represent snow-covered area. The dotted line in the NOAA images represents the area within which the surface temperatures at the time of the satellite overpass had not been above freezing for the week. The heavy black line in the passive-microwave images is the boundary of the NOAA snow extent for the week.

Fall comparison - Fig. 4a (8-14 November 1993)

The underestimate in the presence of shallow snow by the Chang and Goodison algorithms is apparent in both North America and Eurasia. The Nagler and Grody algorithms provide a better estimate as a result of the inclusion of the $85 \mathrm{GHz}$ channel. However, during fall, and throughout the winter, the Nagler and Grody algorithms also tend to overestimate the snow extent in some locations (e.g. in the highelevation deserts of central Asia). The Goodison algorithm appears to also overestimate snow over some desert-soils regions such as the Tibetan Plateau, probably due to the enhanced spectral gradient of the vertical-polarization channel in the presence of frozen ground (Mätzler, 1994). The
Chang and Goodison algorithms falsely indicate snow cover in the presence of storms with high-cloud liquid water, as seen in the southern United States, while these storms are filtered out in the Nagler and Grody algorithms.

\section{Winter comparison - Fig. 4b (16-22 January 1995)}

As snow-cover depth increases, all algorithms show improved estimates of snow extent. A short-duration storm leaving shallow snow in the south-central United States is not detected by Chang or Goodison but is partially detected by Nagler and Grody. Because of the short duration of this snow cover, combined with the fact that these datasets merely characterize weekly time periods, a precise match of the datasets 

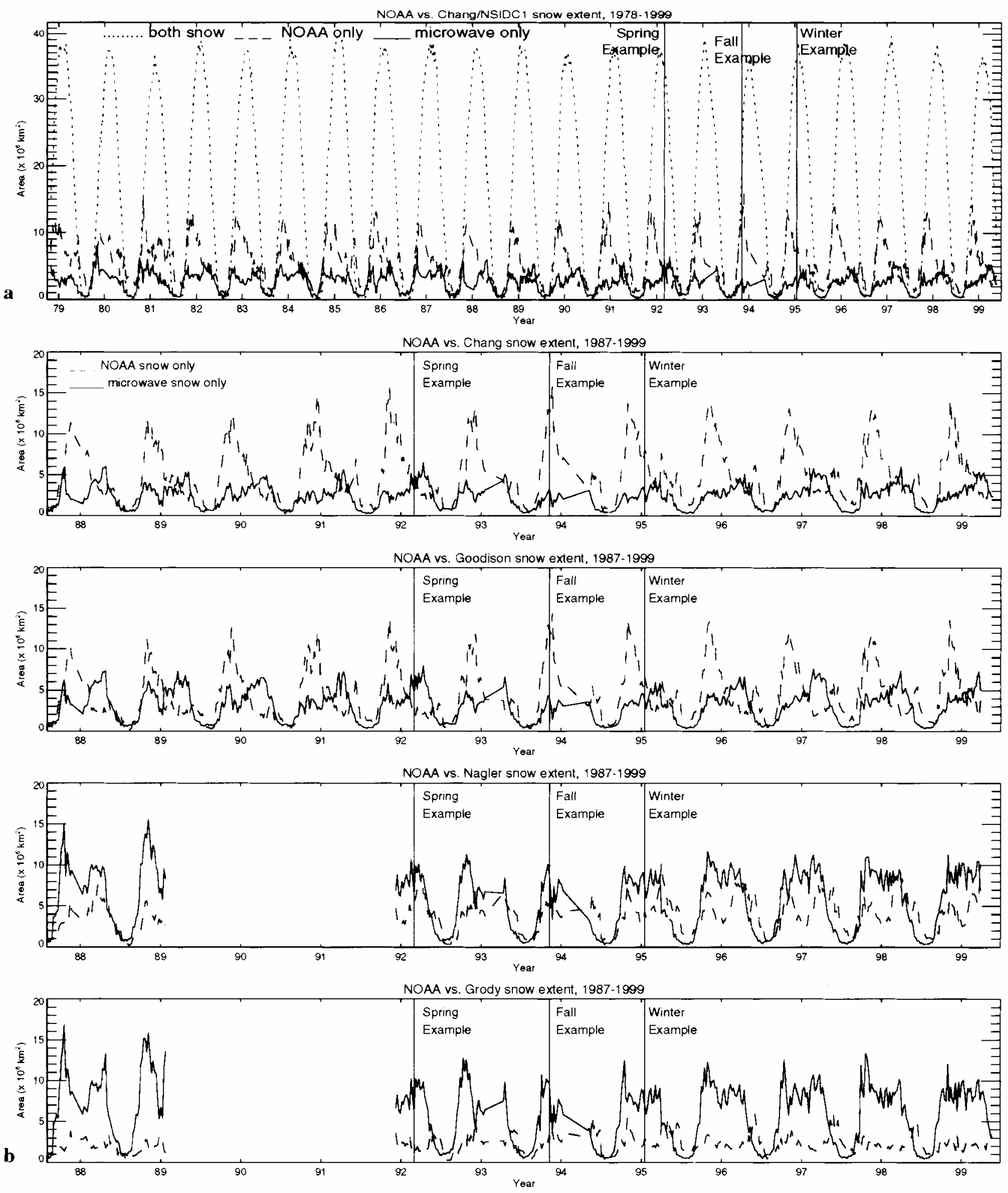

Fig. 5. (a) Time-series comparison of snow extent from NOAA vs Chang (SMMR, 1978-87) and NSIDC1 (SSM/I, 198799) passive-microwave algorithms. (b) Time series of areas of disagreement between NOAA snow extent and the respective microwave algorithms. In each plot, the dashed line represents the area identified as snow by NOAA but missed by the microwave algorithm. The solid line represents the area identified as snow by the microwave but missed by NOAA. $85 \mathrm{GHz}$ data (required by Nagler and Grody algorithms) are not available from SSM/I from 1989 to 1991.

is not to be expected. Goodison appears to continue to overestimate in the Tibetan Plateau, while Grody and Nagler show even larger overestimates in this region and in the Gobi Desert region, east of the Tibetan Plateau.

\section{Spring comparison - Fig. 4c (2-8 March 1992)}

As the snow becomes deeper and the layered structure more complex, the negative spectral gradient driving the algo- rithms is enhanced (Mätzler, 1994). As a result, all algorithms continue to show improved agreement with the NOAA data, with the exception of the apparent overestimates in the high deserts of central and eastern Asia by the vertical polarizations used in the Goodison algorithm and the $85 \mathrm{GHz}$ channel used in the Grody and Nagler algorithms. All algorithms correctly depict the Taklimakan Desert, north of the Tibetan Plateau, as snow-free. Again, warm storms across the southern United States are filtered out by the Nagler and Grody algorithms. 


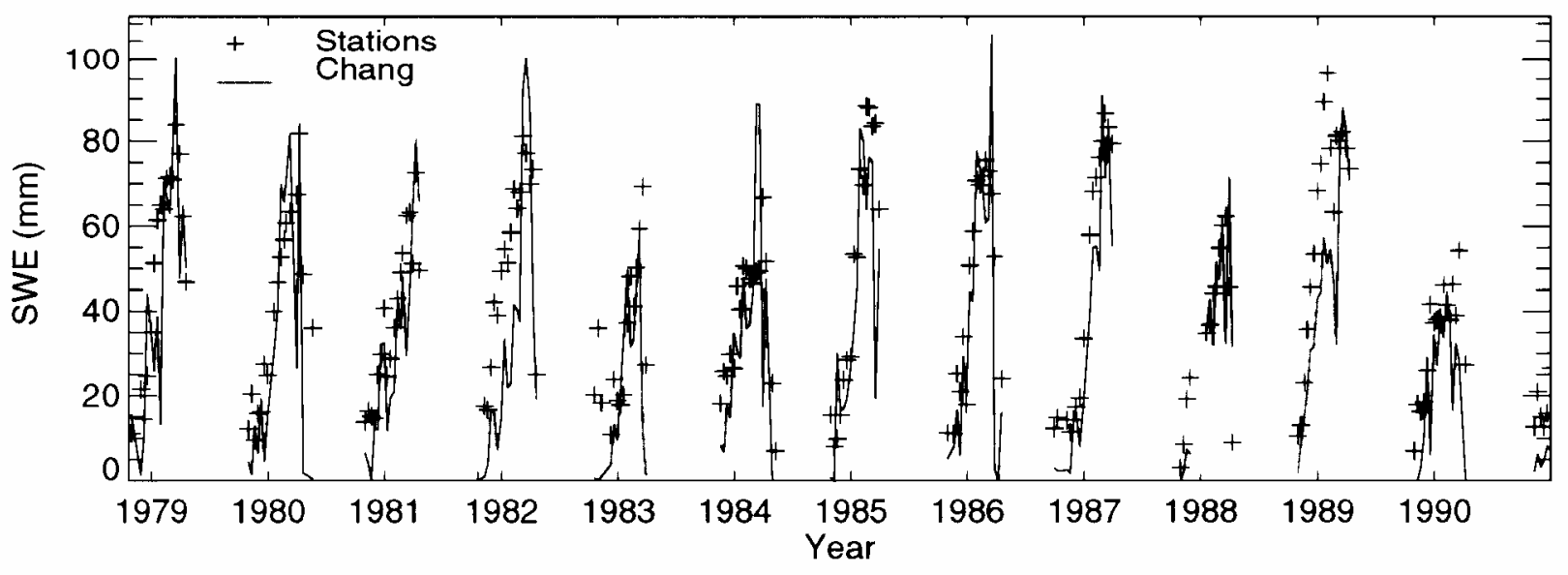

Fig. 6. Average of total study-area (FSUHS subset) SWE vs passive-microwave SWE using horizontally polarized difference algorithm, 1978-90.

Figure 1 showed how the passive-microwave and the visible data provide a similar pattern of interannual variability. Figure $5 \mathrm{a}$ and $\mathrm{b}$ look at this relationship in more detail by providing a time series of the area of agreement and disagreement between NOAA snow extent and the respective microwave algorithms. Figure 5a contains the full timeseries (SMMR and SSM/I) comparison of snow extent from the NOAA data and from one example (Chang) algorithm. The occurrence of the particular seasonal examples shown in Figure 4 is indicated in the time series. Figure 5b, which is limited to the SSM/I period and shows areas of disagreement only, includes the comparison with all four algorithms. In this figure it can be seen that the specific examples of disagreement described in Figure 4 persist as general patterns throughout the time series. For example, the greater area of snow detected by the NOAA data in the fall is apparent, as well as the improved agreement as the winter progresses and the apparent overestimate in some locations throughout the winter by the Nagler and Grody algorithms.

\section{SWE}

In this phase of the study a topographically consistent subset of the FSUHS data was selected for the validation. This subset $\left(45-60^{\circ} \mathrm{N}, 25-45^{\circ} \mathrm{E}\right)$ has the highest station density (approximately one transect per $100 \mathrm{~km}$ gridcell) and is primarily composed of non-complex terrain (grassland steppe) with maximum elevation differences of $<500 \mathrm{~m}$. We have developed a processing environment and output format to compare the various algorithms with the station SWE data. For each station file this involves the combination of the daily brightness-temperature files for the observation date and for the previous 2 days to provide complete spatial coverage for the satellite data. SWE for all pixels containing at least one transect measurement is compared with the output from the respective algorithms. Figure 6 shows a time-series comparison of station data with a single algorithm (Chang and others, 1987) averaged over the total study area for a 12 year period. Figure 7 shows a single-year comparison of three different algorithms. (During 1989, 85V data were not available after 31 January, hence output from the Nagler algorithm terminates on that date.) These preliminary results represent only the initial phase of our efforts to evaluate the accuracy of the microwave SWE algorithms.

\section{GONGLUSIONS AND FUTURE WORK}

Results from the current phase of our study indicate that horizontal polarization-based algorithms (e.g. Chang), while apparently underestimating snow extent during early winter, appear to provide the best overall estimates as winter progresses. Vertical-polarization-based algorithms (e.g. Goodison) provide similar results but with the tendency to overestimate snow extent in the presence of desert soils and/or frozen ground. Algorithms which include the $85 \mathrm{GHz}$ channel (e.g. Grody and Nagler) are capable of detecting shallow snow but in their current form may frequently overestimate snow extent. As the snow cover becomes deeper and the layered structure more complex, all algorithms tend to show improved agreement with the NOAA data.

With respect to SWE, results indicate a general tendency for the algorithms tested thus far to underestimate values

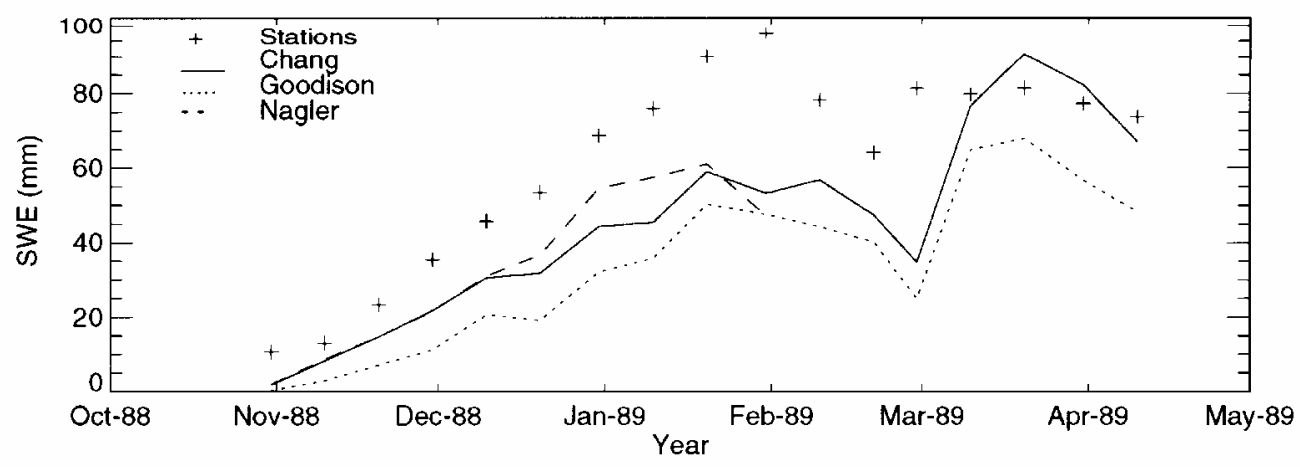

Fig. 7. Average of total study area (FSUHS subset) SWE vs passive-microwave SWE from three algorithms, 1988-89. 
obtained from surface station measurements. Unlike snow extent, differences between the validation data and the microwave algorithms appear to be generally consistent throughout the winter season. Underestimates of SWE increase significantly as the forest-cover density begins to exceed 30-40\%. Because of the detailed land-cover data available for this validation area, we will be able to evaluate the results of algorithm adjustments based on fractional forest cover as proposed earlier by Chang and others (1996). In addition to the time-series comparisons shown in Figures 6 and 7, our analysis is also based on image-subtraction timeseries comparisons which allow evaluation of both temporal and spatial differences. Coupled with additional data on topography, vegetation cover, surface air temperature and snow structure, these spatial comparisons viewed throughout the winter season will provide valuable insight into the actual causes of the observed differences. Future analysis will continue the comprehensive multi-year comparison of at least these four algorithms with the FSUHS data, as well as other surface station measurements in the United States and Canada, and the development of a methodology that will combine visible and passive-microwave data to provide an optimal satellite-derived snow product.

\section{ACKNOWLEDGEMENTS}

This work is supported by NASA Research Grants NAG54906 and NAG5-6636. NGEP Re-analysis data were provided by the NOAA-CIRES (Cooperative Institute for Research in Environmental Sciences) Climate Diagnostics Center, Boulder, CO, from their web site at http://www.cdc.noaa.gov.

\section{REFERENGES}

Armstrong, R. L. and M. J. Brodzik. 1998. A comparison of Northern Hemisphere snow extent derived from passive microwave and visible remote sensing data. In Stein, T., ed. IGARSS '98. 18th International Geoscience and Remote Sensing Symposium, 6-10 July 1998, Seattle, Washington. Proceedings. Vol. 3. Piscataway, NJ, Institute of Electrical and Electronics Engineers, 1255-1257.
Armstrong, R. L. and M. J. Brodzik. 1999. A twenty year record of global snow cover fluctuations derived from passive microwave remote sensing data. In Fifth Conference on Polar Meteorology and Oceanography, 10-15 January 1999, Dallas, Texas. Proceedings. Boston, MA, American Meteorological Society, 113-117.

Barron, E. J., D. L. Hartmann, M. D. King, D. S. Shimel and M. R. Schoeberl, 1999. EOS science plan: the state of science in the EOS program. Greenbelt, MD, NASA/Goddard Space Flight Center.

Brown, R. D. 2000. North American snow cover variability and change, 1917-97. . Climate, 13(7), 2339-2355.

Chang, A. T. C., J. L. Foster and D. K. Hall. 1987. Nimbus-7 SMMR derived global snow cover parameters. Ann. Glaciol., 9, 39-44.

Chang, A. T. C., J. L. Foster and D. K. Hall. 1996. Effects of forest on the snow parameters derived from microwave measurements during the BOREAS winter field campaign. Hydrol. Processes, 10, 1565-1574.

Frei, A. and D. A. Robinson. 1999. Northern Hemisphere snow extent: regional variability 1972-1994. Int. F. Climatol., 19(14), 1535-1560.

Goodison, B. E. 1989. Determination of areal snow water equivalent on the Canadian Prairies using passive microwave satellite data. In International Geoscience and Remote Sensing Symposium (IGARSS). Quantitative remote sensing: an economic tool for the nineties. 12th Canadian Symposium on Remote Sensing, Vancouver, British Columbia, 10-14 July 1989. Proceedings. Vol. 3. New York, Institute of Electrical and Electronics Engineers, 1243-1246. (IEEE \#89CH2768-0.)

Grody, N. and A. Basist. 1996. Global identification of snowcover using SSM/I measurements. IEEE Trans. Geosci. Remote Sensing, GE-34(1), 237-249.

Groisman, P. Ya., T. R. Karl and R.W. Knight. 1994. Observed impact of snow cover on the heat balance and the rise of continental spring temperatures. Science, 263(5144), 198-200.

Haggerty, C. D. and R. L. Armstrong. 1996. Snow trends within the Former Soviet Union. [Abstract.] Eos, 77(46), Fall Meeting Supplement, F191.

Hiltbrunner, D. 1996. Land surface temperature and microwave emissivity from SSM/I data. (Ph.D. thesis, University of Bern. Institute of Applied Physics.)

Mätzler, C. 1994. Passive microwave signatures of landscapes in winter. Meteorol. Atmos. Phys., 54, 241-260.

Nagler,T. 1991. Verfahren zur Analyse der Schneebedeckung aus Messungen des SSM/I. (Diplomarbeit thesis, University of Innsbruck.)

Pulliainen, J. and M. Hallikainen. 2001. Retrieval of regional snow water equivalent from space-borne passive microwave observations. Remote Sensing Environ., 75(1), 76-85.

Robinson, D. A., K. F. Dewey and R. R. Heim, Jr. 1993. Global snow cover monitoring: an update. Bull. Am. Meteorol. Soc., 74(9), 1689-1696.

Tait, A. 1998. Estimation of snow water equivalent using passive microwave radiation data. Remote Sensing Environ., 64(3), 286-291.

Walker, A. E. and B. E. Goodison. 1993. Discrimination of a wet snowcover using passive microwave satellite data. Ann. Glaciol., 17, 307-311. 